\title{
Application of Standardized Observation Form in School Counselling in Taiwan: Exploratory Study with Children Exhibiting Internalizing and Externalizing Behavior Concerns
}

\author{
Mei-Hsiang Tsai ${ }^{1}$ \\ ${ }^{1}$ National University of Tainan, Taiwan \\ Correspondence: Mei-Hsiang Tsai, National University of Tainan, Taiwan
}

Received: April 8, 2018

Accepted: April 28, 2018

Online Published: May 1, 2018

doi:10.5539/ijps.v10n2p25

URL: https://doi.org/10.5539/ijps.v10n2p25

\begin{abstract}
The exploratory study investigated the impact of Child-Centered Play Therapy (CCPT) on children who present with internalizing and externalizing behavioral concerns through a single-case design. Two second-grade male children in northern Taiwan displaying clinical levels of internalizing or externalizing behavior problems underwent 9 weeks of weekly 40-minute CCPT sessions. The children's parents and teachers completed the Child Behavior Checklist and Teacher's Report Form before and after play therapy. Observational data were collected via the Direct Observation Form throughout the baseline, intervention, and follow-up phases. Observation data were evaluated through visual analysis. In-session play therapy notes and the children's play therapy behavior scores were also analyzed. The participants' internalizing and externalizing problem behaviors demonstrated slight decreases.
\end{abstract}

Keywords: child-centered play therapy, externalizing behavior problem, internalizing behavior problem, observation, school counselling

\section{Introduction}

In the past 5 years, enormous changes in education legislation in Taiwan have drawn greater attention to students' mental health. Article 10 of the Primary and Junior High School Act was revised in January of 2011 (Ministry of Education in Taiwan, 2011). Article 10 required Taiwan's primary and junior high schools to establish counselling centers and increase the number of school counselors or social workers available to provide mental health services for children and adolescents. Additionally, the Student Guidance Act, first enacted in October of 2014, required the implementation of primary, secondary, and tertiary measures for promoting students' mental health (Ministry of Education in Taiwan, 2014). Because schools play a role in enhancing children's well-being, schools have begun needing to incorporate evidence-based practices (EBP) and assessments into school settings.

While providing counseling services in the schools, therapists need to be sensitive to the cultural, ethnic, and gender roles within diverse individuals and their families so as to build therapeutic relationships (O'Connor, Schaefer, \& Braverman, 2016). Hwang (2012) indicated that Confucian ethics and philosophy address self-cultivation, harmony, and balances are still crucial in Chinese culture. Counseling clinicians are advised to explore a child's inner drive toward self-realization and affirmation of the worthwhileness of self within the social norms.

According to the Centers for Disease Control and Prevention (CDC, 2013), an estimated $13 \%$ to $20 \%$ of children in the United States experience mental disorder symptoms in a certain year. Investigation during 1994 through 2011 revealed an increasing prevalence of childhood disorders (CDC, 2013). Results of a parent-reported investigation demonstrated that attention-deficit/hyperactivity disorder (ADHD) among children aged 3 to 17 years was $6.8 \%$, representing the most prevalent childhood mental disorder. ADHD was followed by behavioral or conduct problems at $3.5 \%$, anxiety at $3.0 \%$, depression at $2.1 \%$, autism spectrum disorders at $1.1 \%$, and Tourette syndrome at $0.2 \%$ among children aged 6 to 17 years (Soni, 2014). Furthermore, the World Health Organization (WHO, 2015) reported $10 \%$ to $20 \%$ of children and adolescents experience mental disorders worldwide. Lack of treatment for children with mental health problems has led to negative long-term outcomes that include lack of educational attainment, poor future work performance, and future psychosocial and 
economic well-being deficits (Copeland, Shanahan, Costello, \& Angold, 2009). Hence, early detection, providing evidence-based treatment, and promoting mental well-being in young people have become major public health goals (MHA, 2009; WHO, 2014).

To distinguish mental health issues among children, Achenbach (1966) identified the terms 'internalizing' and 'externalizing'. Internalizing behaviors refer to behaviors symptomatic of an attempt to cope with internal conflicts and operating as an inward expression of experience, such as showing signs of withdrawal, anxiety, or depression. Externalizing behaviors refer to behaviors expressing an inner conflict or problem outwardly or toward others (Achenbach \& Rescorla, 2001). A body of literature includes evidence that children's and adolescents' internalizing and externalizing behavior problems could affect their peer relationships (Dishion \& Patterson, 2006; Sturaro, Van Lier, Cuijpers, \& Koot, 2011), familial relationships (Chengappa et al., 2013; Marchand-Reilly, 2012), and self-control (Schoemaker, Mulder, Dekovic, \& Matthys, 2013; White, Jarrett, \& Ollendick, 2013). Additionally, children with internalizing and externalizing behavior problems experience academic difficulties (Blanco, Ray, \& Holliman, 2012; Masten et al., 2005; Rubin, Coplan, \& Bowker, 2009). In a longitudinal study, Masten and colleagues (2005) examined the relationship between externalizing and internalizing behaviors and academic competence over a 20 -year span and found an inverse relationship between externalizing behavior and academic achievement. Because children's expressions of externalizing and internalizing behavior s have long-lasting effects on their cognitive (Piaget, 1962), emotional (Vygotsky, 1967), and social development (Erikson, 1977), decreasing the impact and risk of mental concerns for all youth becomes an imperative for child development professionals, school counselors, parents, and teachers (Herrman, Goldstone, \& McGorry, 2014). In this study, internalizing and externalizing behaviors are operationally defined according to Achenbach and Rescorla's (2001) classifications.

\subsection{Play Therapy}

\subsubsection{Play Therapy and Internalizing and Externalizing Behaviors}

The Association for Childhood Education International (ACEI, 2015) highlighted the value and crucial role of play in children's lives. Play is the natural and primary means of communication for children; hence, play is vital to child development and provides the social, physical, cognitive, and emotional well-being of children (Ginsburg, 2007; Russ, 2004; Vygotsky, 1967). To enhance children's well-being, play therapy provides a universal and non-verbal method for children to express themselves and to bridge the gap between abstract and concrete worlds (Landreth, 2012).

Empirical studies have shown the efficacy of play therapy with a variety of childhood emotional and behavioral concerns (Bratton, Ray, Rhine, \& Jones, 2005; Lin \& Bratton, 2015; Wang, Jang, Lian, \& Wang, 2006). Specifically, Ray, Armstrong, Balkin, and Jayne (2015) reviewed studies addressing child centered play therapy in elementary schools and found it to be an efficacious treatment for internalizing problems, externalizing problems, total problems, self-efficacy, academic, and other concerns. Results from the above four meta-analyses provided evidence in support child centered play therapy with school-aged children.

\subsubsection{Play Therapy with Children Exhibiting Internalizing Problems}

All children, regardless of their quality of adjustment, show similar types of negative attitudes such as hostility or fear (Moustakas, 1955). The main difference between maladaptive and well-adjusted children depends on the quantity and intensity of such attitudes. Well-adjusted children convey negative attitudes less frequently and with less intensity than maladaptive children; their expressions of negative attitudes appear more focused and directed (Landreth, 2012).

Moustakas (1955) stated that an emotionally maladaptive child's perceptions toward self are usually negative. The child then experiences feelings of fear and anger. Hostility is viewed as a primary outer source, whereas anxiety is viewed as an internal attitude. Although hostility and anxiety cannot completely be separated, one is often expressed more significantly than the other (Horney, 1937; Korner, 1949). Moustakas further proposed that maladaptive children operate on an anxiety-hostility cycle:

As he outwardly expresses hostility, his feelings of guilt increase and his inner anxiety is intensified. As he expresses his anxiety, he feels more and more hostile. When he becomes more angry inside he expresses more fear outside, and when he expresses more fear he becomes angrier inside. (pp. 82-83)

In Child-Centered Play Therapy (CCPT), therapists assist children's abilities to express fear, anxiety, and depression as part of accepting the therapeutic relationship. By exploring feelings, children in CCPT gain inner comfort, pleasure, worthiness, and adequacy. Accordingly, both feelings of inadequacy and levels of anxiety decrease within children undergoing CCPT (Moustakas, 1955). In other word, therapeutic relationship plays a 
significant role in the process of change in CCPT.

Nordling and Guerney (1999) presented a four-stage model to comprehend the therapeutic process in CCPT, including the warm-up, aggressive, regressive, and mastery stages. Within each stage, children are likely to exhibit certain types of play behavior $\mathrm{s}$ and play themes. Therapists must respect each child's uniqueness and accept each child for exactly who he or she is. As a consequence, each child accepts the self. When children's sense of self-significance and self-adequacy grow, anxiety decreases. With progress in treatment, the therapeutic relationship between the child and the play therapist strengthens. In summary, the therapeutic relationship is key to decreasing children's internalizing problem behavior s (Carmichael, 2006; Guerney, 2001; Landreth, 2012; VanFleet, Sywulak, \& Sniscak, 2010). Moreover, treatment effects of CCPT on children's internalizing behavior concerns are evident in the literature (Baggerly \& Jenkins, 2009; Cheng \& Tsai, 2014; Ray, Schottelkorb, \& Tsai, 2007; Wettig, Coleman, \& Geider, 2011).

\subsubsection{Play Therapy with Children Exhibiting Externalizing Problems}

A body of literature has demonstrated the effectiveness of CCPT with children who exhibiting externalizing behavior concerns (Ray, Blanco, Sullivan, \& Holliman, 2009; Schoemaker et al., 2013; Trice-Black, Bailey, \& Riechel, 2013; Tsai \& Ray, 2011). Children's expression of externalizing behavior may reveal inner conflict that is demonstrated outwardly. Children exhibiting externalizing problem behavior s may break more limits and display more aggressive behavior $\mathrm{s}$ in the playroom. When dealing with this specific problem, limit-setting is important. Axline (1969) indicated that consistent limits offer children a sense of security and prevent them from experiencing guilt when attempting to violate accepted societal norms. When therapists set consistent limits appropriately, play therapy provides an opportunity for children to learn self-control.

In CCPT, the play therapists state the limit-setting responses in an empathic way (Ray et al., 2009; West, 1996). By limit-setting in an empathic way, play therapists deliver the message that they understand their clients, the children, want to cross the line, and they demonstrate that they accept the children's feelings. By experiencing acceptance from their play therapists, children accept themselves as unique individuals. However, therapists do not allow children to break limits during CCPT. Limit setting enables child-centered play therapists to deliver warmth, genuineness, and empathy to children within the therapeutic relationship (Cochran, Cochran, Cholette, \& Nordling, 2011; Landreth, 2012).

Mills and Allan (1992) described the stages of CCPT with children exhibiting aggressive behavior s. In the beginning stage, play therapists provide a safe and trusting environment for children to experience the sense of security to express feelings. In the second stage, through re-experiencing acceptance and security, children's inner growth tendencies increase. At the same time, children's anxiety and ambivalence levels increase and limit-testing behavior s occur. As indicated earlier, play therapists impose consistent limits in an empathic way. Once children feel safe, understood, and accepted, they use the therapeutic relationship to work on previous issues in the third stage. As the play intervention progresses through stages, children display less aggressive behavior $\mathrm{s}$ and engage in more interactive play in the last stage.

\subsubsection{Play Therapy and Evidence-Based Practice}

Considering the current move to implement mental health interventions in Taiwanese schools as well as efforts to make counselling practice more scientific, EBP provides the guidance practitioners need to carry out empirically supported interventions. EBP has been emphasized as valuable to social work and counselor professional development (Okpych \& Yu, 2014; Purswell \& Ray, 2014; Rubin \& Parrish, 2012).

The American Psychological Association's (2008) Task Force on Evidence-Based Practice with Children and Adolescents addressed three primary components of an evidence-based clinical practice: (a) using assessments that provide guidelines for intervention, diagnosis, and effect evaluation; (b) utilizing an intervention that validates empirical support for the target populations; and (c) offering ongoing monitoring in a scientifically minded manner and with client feedback. To promote children's mental health, identification of effective treatments and validated research methodologies is essential. As such, single-case research design could meet the requirements for empirically supported interventions and has been used in the past (Okpych \& Yu, 2014; Rubin, 2012). Additionally, research using single-case design methodology provides a means for scholars and practitioners to recognize a participant's functioning over time, to explain individual emotional and behavioral changes, and to enhance the evidence-based mental health field. Scholars have underscored the applicability of single-case design in child counselling research and in school settings (McDougall \& Smith, 2006; Morgan \& Morgan, 2009; Ray, Minton, Schottelkorb, \& Brown, 2010).

Paynter (2009) used a pyramid to illustrate the hierarchy of evidence quality for mental health interventions' 
practice guidelines/manuals. At the bottom of the hierarchy are qualitative studies and therapists' clinical experiences. Above experiences are randomized controlled trials and quantitative studies. At the top are systematic reviews and meta-analyses of previously conducted studies. Based on Paynter's (2009) hierarchy of evidence quality, Ray and McCullough (2015) reviewed and summarized 65 play therapy studies published from 2000 to 2015 and involving samples of children aged 3 to 12 years old. Ray and McCullough revealed play therapy is effective with children exhibiting diverse concerns that include internalizing or externalizing problems, self-efficacy, academic, and so on. They also found play therapy to be efficacious with children representing a number of multicultural nationalities and backgrounds including African American, Biracial, Caucasian, Hispanic, Indian, Iranian, Taiwanese, and Swiss.

Tsai (2013) compiled a comprehensive literature review on play therapy conducted in Taiwan. The sample included 86 master's theses and doctoral dissertations published from 2001 to 2010. The results revealed that $68.6 \%$ were qualitative, $8.1 \%$ were quantitative, and $23.3 \%$ were mixed methods. Tsai also indicated EBP with play therapy in Taiwan was scarce.

The purpose of the current study was to investigate the impact of CCPT with children exhibiting internalizing or externalizing behavior concerns. Inclusion of the in-session play therapy assessment into child research and cultural considerations for use of CCPT in school-settings in Taiwan occurred. The single-case research design was used to examine the effectiveness of counselling interventions and to explore the appropriateness of CCPT in school settings in Taiwan. Additionally, the Directive Observation Form and in-session play therapy notes were utilized to collect data about each child's behavior changes. This study was conducted to enrich the EBP movement in Taiwan. The main question of concern in the present study asked: What was the impact of CCPT with a child exhibiting internalizing or externalizing behavior problems?

\section{Method}

\subsection{Participants}

This exploratory study involved investigating the application of standardized observation forms and in-session progress during child counselling for examining the impact of CCPT with children presenting internalizing and externalizing behavior concerns in Taiwan. Because this study was conducted in the fall semester, first-grade teachers were difficult to identify students who might exhibit emotional or behavioral problems within the first two weeks of school. Thus, second-grade students were recruited for the study. To facilitate early identification and early intervention, a research explanation meeting with second-grade teachers in an elementary school in northern Taiwan was conducted. The teachers then completed the Teacher's Report Form (TRF) as a screening tool for students. Students with a $T$ score above 64 (clinical range) on Internalizing or Externalizing Problems on the TRF were recruited for the study. Due to the nature of this exploratory study, two second-grade 8-year-old male students were recruited. Participant A exhibited internalizing behavior problems, and Participant B displayed externalizing behavior problems. The two participants' parents and teachers completed the CBCL and TRF prior to and after play therapy, respectively. At the time of the completion of play therapy, individual feedback was provided for children's teachers and parents. Children referred for the study by their teachers, but not selected to participate in the study, were referred to the student counselling center for further assistance.

\subsection{Procedures}

Play therapy procedure. Individual CCPT was conducted in 40-minute weekly sessions for 9 weeks by a licensed counseling psychologist, for a total of 360 minutes in play therapy. The play sessions were conducted in a specially equipped playroom with a variety of selected toys in the students' elementary school. Based on Landreth's (2012) guidance on play materials, the selected toys included real-life toys (e.g. dollhouse, doll family, and cash register), acting-out aggressive-release toys (e.g. aggressive plastic animals, bobo, rubber knife, and dart gun), and creative expression and emotional release toys (e.g. sand, water, paint, and crayons). The specific selection of therapeutic toys enabled the therapist and children to establish a positive relationship and the children's expression of various feelings, development of self-understanding and self-esteem, discovery of real-life experience, and opportunities for gaining self-control during the period of play therapy (Landreth, 2012; Ray, 2011).

The principles of CCPT were followed in the play therapy sessions using specific verbal and nonverbal skills. The reflective nonverbal responses included the following: (a) leaning forward toward the child at all times and maintaining open posture; (b) appearing interested in the child throughout the play session; (c) appearing comfortable and remaining relaxed; (d) matching the level of affect displayed by child through tone and rate of speech; and (e) conveying a sense of genuineness by matching words and affect. Additionally, the reflective verbal responses involved a number of specific counselling skills: (a) utilizing short, interactive, and 
personalized responses; (b) tracking children's play behaviors; (c) reflecting content; (d) reflecting feeling; (e) facilitating decision-making and returning responsibility; (f) using esteem-building responses and encouragement; and (g) facilitating the relationship (Carmichael, 2006; Landreth, 2012; Landreth, Ray, \& Bratton, 2009).

Observation procedure. The research team included one faculty member, one licensed counselor, and one counselling graduate student. The play therapist was a master-level licensed counseling psychologist with five years of experiences in play therapy.

Prior to formal observation, a regular class in a second-grade classroom was videotaped after the teacher provided informed consent. The faculty member and the trained observer watched the videotape for 10 minutes and filled out the Direct Observation Form (DOF). The initial inter-rater agreement of Cohen's (1988) coefficient of agreement was .82. The faculty member and the trained observer discussed variations of evaluations of responses and clarified interpretations of specific observed children's behaviors. Following viewing another 10-minute segment, the faculty member and the trained observer completed the DOF again.

The Cohen's coefficient of agreement was increased to .92, due to these efforts. Based on Landis and Koch's (1977) principles, the inter-rater reliability was in almost perfect agreement $(0-.20=$ slight, $.21-.40=$ fair, .41 - .60 = moderate, $.61-.80=$ substantial, and $.81-1.0=$ almost perfect). Once inter-rater reliability was established, the trained observer used the DOF for in-class observations of both research participants for ten minutes, twice a week. The observation data were collected twice a week during the baseline phase ( 3 weeks), the intervention phase ( 9 weeks), and the follow-up phase ( 3 weeks), for a total of 15 weeks. Each participant received 30 observation scores and the total time spent in in-class observations for each child was 300 minutes. Assessment Data Manager (ADM) software was utilized for DOF data entry and analyses.

\subsection{Instruments}

Direct observation form. The DOF (McConaughy \& Achenbach, 2009) is a 10-minute observation instrument for examining a 6- to 11-year-old child's behavior within a group, classroom, or recess setting. A trained observer rates a student's on- and off-task behavior for 5 seconds at the end of each 1-minute interval. Once the observation is ended, the observer rates a child on 89 problem items using a 0 to 3 scale, ranging from $0=$ behavior was not observed to $3=$ definite occurrence of behavior with severe intensity or lasting more than 3 minutes in duration. Examples of observations are "physically isolated self from others" or "disrupts group activities".

The DOF classroom observation scales are Sluggish Cognitive Tempo, Immature/Withdrawn, Attention Problems, Intrusive, Oppositional, Total Problems-Classroom, DSM-oriented Attention Deficit/Hyperactivity Problems with Inattention and Hyperactivity-Impulsivity subscales, and On-task. The inter-rater reliabilities on each scale for classroom observations ranged between .7 and .97 , with the mean of .8 across the five syndromes and Total Problems and with an overall mean of .79 across all DOF problem scales (McConaughy \& Achenbach, 2009). The content validity of the DOF items was derived from similar items of the CBCL/6-18 and TRF. Achenbach and Rescorla (2001) indicated that most of the DOF's items significantly discriminated between referred and non-referred children. Once all observations were completed, ADM software was used to compute each child's average scores for further analysis. Ethnicity of Asian was selected for scoring.

To establish the DOF's reliability and validity for classroom observations, 661 normative samples were recruited, and $2.1 \%$ were Asian children. According to the DOF manual, there were 22 items related to demographic effects, accounting for $1 \%$ to $5 \%$ variance (McConaughy \& Achenbach, 2009). Among these 22 items, eight could be counted as chance effects. Children identified as the "Other" ethnicity were rated higher than non-Latino White children on 20 DOF items, while non-Latino White children were rated higher on two items (McConaughy \& Achenbach, 2009, p. 103).

Child behavior checklist. The CBCL (Achenbach \& Rescorla, 2001) is an instrument that measures parents' reports of children's competencies as well as behavioral and emotional problems, according to children's activities, social relationships, and school performance. Chen, Huang, and Jao (2009) translated the CBCL for the CBCL Chinese version and established the CBCL Chinese version's norm profiles. CBCL consists of 118 items. Each item is ranked on a 3-point frequency of behavior scale involving $0=$ not true; $1=$ somewhat or sometimes true; 2 = very true or often true. Each item describes a specific behavioral and emotional problem. The instrument offers two open-ended questions for reporting additional problems. Sample items are "demands a lot of attention" or "temper tantrums or hot temper".

CBCL reports clinical behaviors according to three domains of Internalizing, Externalizing, and Total Problems 
that comprise eight syndrome scales including Anxious/Depressed, Withdrawn/Depressed, Somatic Complaints, Social Problems, Thought Problems, Attention, Aggression, and Rule-Breaking Behavior. Each subscale and factor score can be computed to determine $T$ scores and percentiles. $T$ scores above 64 are considered clinically problematic. Scores between 60 and 63 are considered borderline problematic.

The test-retest Pearson correlations for the Internalizing, Externalizing, and Total Problems scales were .91, .92, and .94, respectively. Furthermore, the test-retest Pearson correlations for all CBCL subscales ranged between .80 and .90 , with the average being .89 . The CBCL demonstrates good test-retest reliability and strong validity in discriminating between referred and non-referred children (Achenbach \& Rescorla, 2001). In the present study, the norm profiles of Group 2 were selected for scoring purposes.

Teacher's report form. The TRF (Achenbach \& Rescorla, 2001) is similar to the CBCL and is utilized to investigate teachers' perspectives of students' behavior and emotional issues. Chen, Huang, and Jao (2009) also translated the TRF for the TRF Chinese version and authenticated the TRF Chinese version's norm profiles. Like the competence scores of the CBCL, problems scores, and DSM-oriented scores, the TRF syndrome profiles are computed and represented in the same manner as the CBCL. Sample items address "fears going to school" or "disobedient at school". The test-retest Pearson correlations for the Internalizing, Externalizing, and Total Problems scales were $.86, .89$, and .95 , respectively. Additionally, the test-retest Pearson correlations for TRF subscales ranged between .80 and .90 (except for Withdrawn/Depressed, $r=.60$, and Thought Problems, $r=.72$ ), with an average of .85 , indicating high reliability for the TRF. Strong validity evidence has been obtained in numerous studies conducted over the last 20 years (Achenbach \& Rescorla, 2001). Similar to CBCL, norm profiles of Group 2 were used for scoring purposes.

Assessment of play therapy in-session progress. To investigate a child's play progress on an individual level, Ray (2011) developed a list of dichotomous characteristics to offer a continuum of measurement for the play therapist. The categories of dichotomous characteristics of play behaviors include Self-Directed Play (dependence on therapist for play initiative versus child-directed play), Energy (low energy versus high energy), Sustained Play Behaviors (inability to sustain play or carry out play scene versus sustained play behavior), Destructive (destructive versus constructive), Messy (messy versus clean), Play Involvement of Therapist (play alone versus involvement of therapist in play), Affect (no affect observed versus intensity of affect expressed), Positive Affect (negative affect versus positive affect), Age-Appropriate Play (regressed play versus age-appropriate play), and Frustration Tolerance (inability to tolerate frustration versus high level of frustration tolerance). On each in-session play therapy note, the play therapist used scores of 1 to 10 to assess the child's play behaviors.

\subsection{Data Analysis}

Counseling scholars have recommended the use of single-case design as a way to meet evidence-based practices (EBP) standards when $N$ of research participants is small (Gallo, Comer, Barlow, 2013; Ray et al., 2010). A typical single-case design could be marked as ABA, which referring to A (baseline phase), B (intervention phase), and A (follow-up phase) (Morgan \& Morgan, 2009).

To analyze data in the baseline, intervention, and follow-up phases on the DOF, the data were evaluated through visual analysis (Gast, 2010; Kazdin, 2011). The focus of visual analysis was magnitude and rate, including within-phase and between-phase changes. The within-phase changes contained condition length, level, and trend; the between-phase changes included the change of level, mean level, trend direction, and trend stability as well as the percentage of overlap (Tawney \& Gast, 1984).

The scores of in-session play therapy progress were collected and analyzed by trend illustrations. First, scatterplots of each category of play behavior were plotted. Then the line of best fit for the scatterplots was developed using SPSS software to determine the linear trend. Based on the linear trend, the linear equation and R-squared were computed via SPSS. According to the movement from one direction to the other, the play therapist evaluated the improvement of the child. In addition, the children's teachers and parents completed the pre- and post- TRF and CBCL. The $T$ scores of Internalizing and Externalizing Problems on TRF and CBCL were examined to determine the effect of play intervention.

\section{Results}

\subsection{Participant with Internalizing Behavior Problems}

Visual analysis. To investigate Participant A's internalizing behavior, the $T$ scores for the Immature/Withdrawn subscale on the DOF underwent visual analyses. The mean $T$ scores on baseline, intervention, and follow-up phases were 67, 63, and 70, respectively, with a mean of 66.7. During the baseline phase, the 
Immature/Withdrawn subscale indicated a stable trend. The level ranged from 63 to 70 , with a level change of -3 .

During the intervention phase, the $T$ scores demonstrated an unstable status, with a trend stability of $77.8 \%$. The level ranges were between 50 and 71, with a mean of 57 and a level change of 13 . In the follow-up phase, the mean of $T$ scores was 54.3 , and the trend stability was $100 \%$, indicating a stable situation. According to the between-phases visual analysis, Participant A's level change from baseline phase to intervention phase was -3 , trend direction was from increasing to decreasing, and the percentage of overlap was $22.2 \%$, all demonstrating an effective intervention. From intervention phase to follow-up phase, the trend direction was from decreasing to decreasing, and the percentage of overlap was $100 \%$, indicating that the effect of play therapy was maintained in the follow-up phase. Figure 1 indicates the trend and level of $T$ scores on the Immature/Withdrawn subscale during Participant A's different phases.

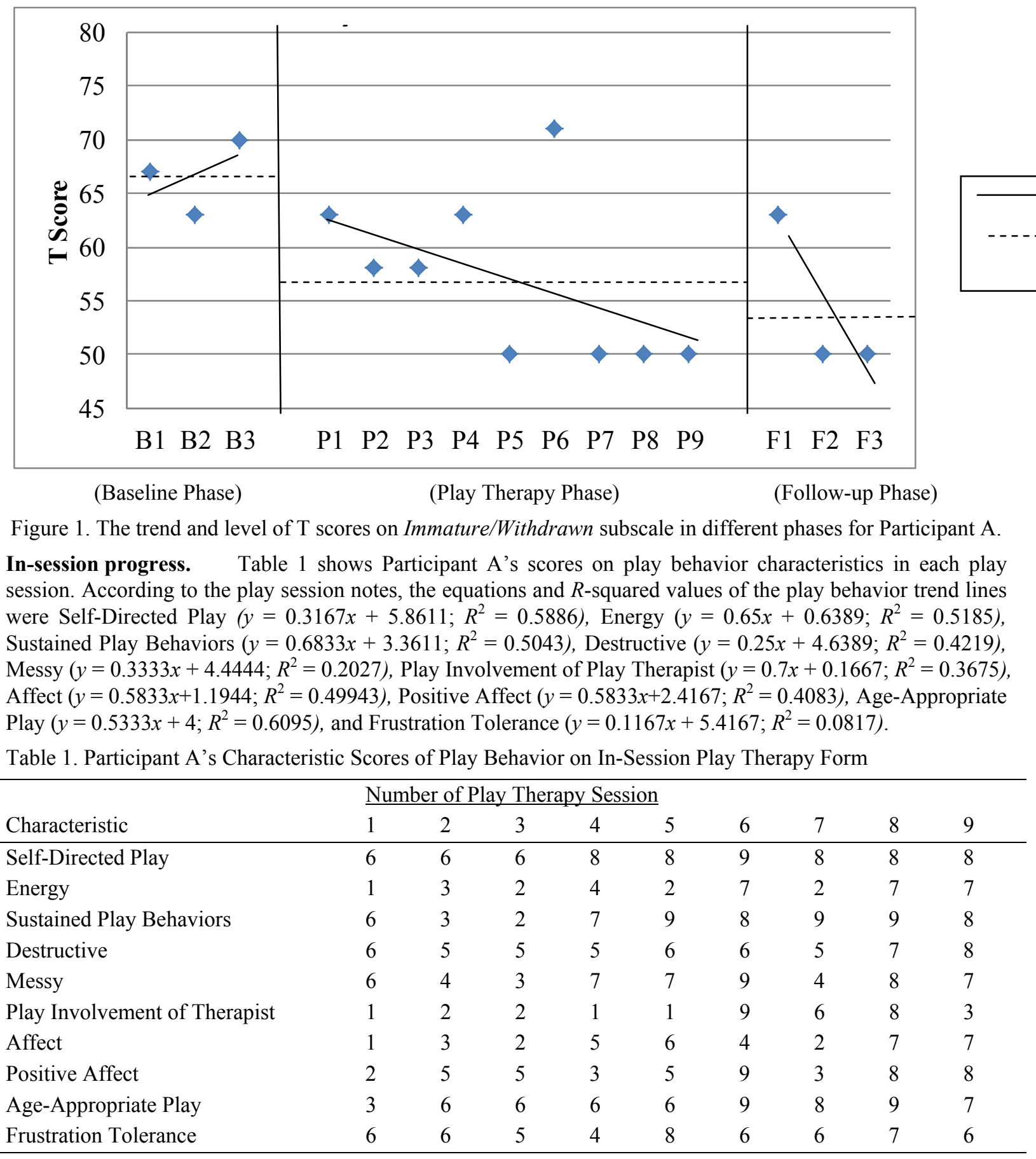


The trend directions for all of the above 10 play behaviors were increasing, indicating that the child's changes were from negative affect to positive affect, low level of energy to high level of energy, easily distracted to focused in play, and so on. As an illustration, Figure 2 represents Participant A's trends of Energy and Sustained Play Behaviors. Based on the findings, Participant A's play behaviors showed improvement and progress after receiving CCPT.

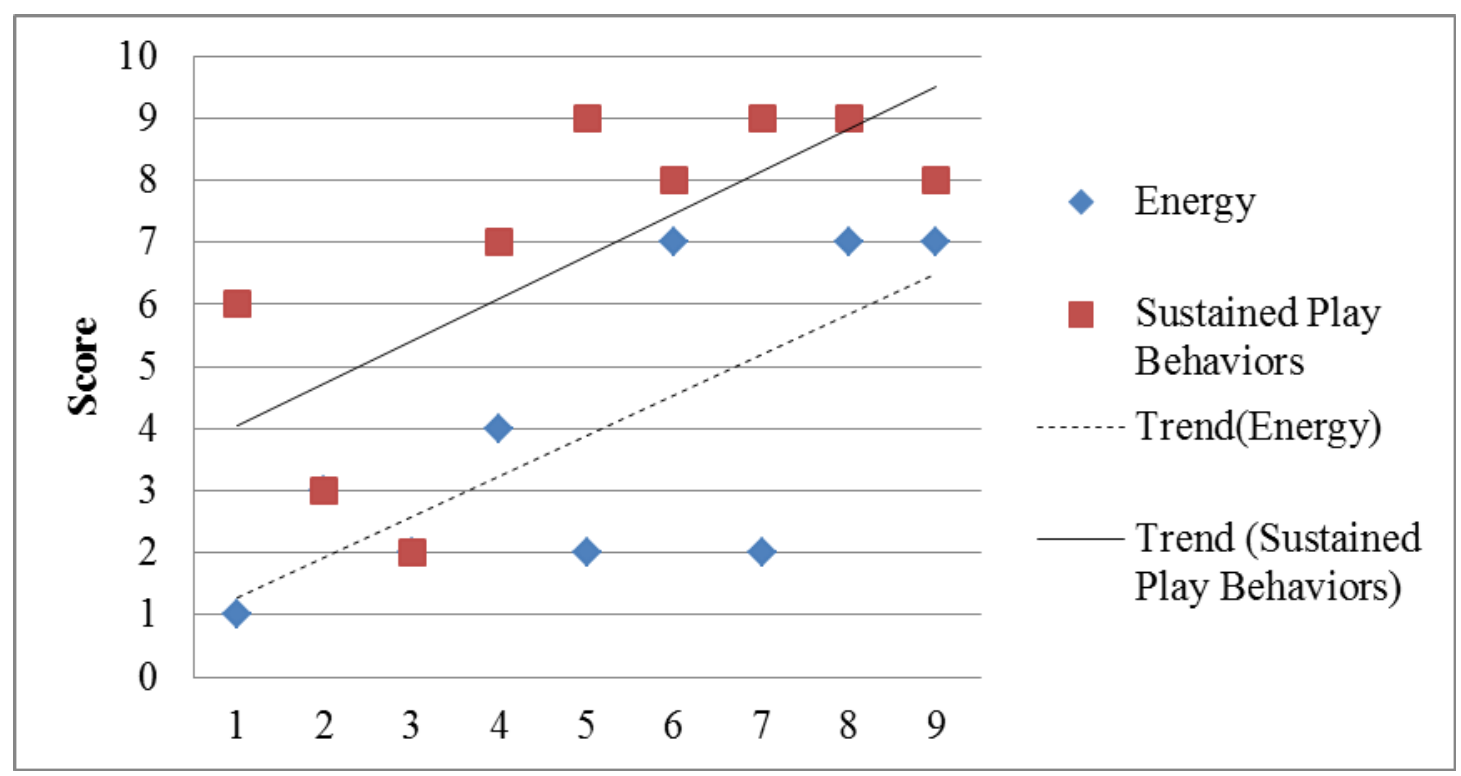

Weeks

Figure 2. The trends of Energy and Sustained Play Behaviors through play therapy sessions for Participant A.

Intervention effect. As for Participant A, the T scores for the Internalizing Problems subscale were 54 and 50 on the pre- and post-CBCL, and were 68 and 56 on the pre- and post-TRF. Individual CCPT showed a treatment effect occurred that was demonstrated by the fact that the participant scored in the Clinical range on the TRF prior to play therapy and in the Normal functioning range following play therapy.

\section{Participant with Externalizing Behavior Problems}

Visual analysis. To examine Participant B's externalizing behavior, the DOF's Oppositional subscale scores were used for visual analysis. The mean $\mathrm{T}$ scores on baseline, intervention, and follow-up phases were 51, 60, and 68, respectively, with a mean of 59.7. During the baseline phase, the oppositional behaviors revealed a stable trend. The level ranged from 51 to 68 , with a level change of -17. During the intervention phase, the T scores indicated a stable status, with a trend stability of $88.9 \%$. The level ranges were between 50 and 66 , with a mean of 54 and a level change of -4 . In the follow-up phase, the mean $\mathrm{T}$ score was 51.3 , and the trend stability was $100 \%$, indicating a stable situation.

Based on the visual analysis of between-phases, Participant B's level change from baseline phase to intervention phase was -17 , the trend direction was from increasing to decreasing, and the percentage of overlap was $66.7 \%$, demonstrating a small intervention effect. From intervention phase to follow-up phase, the trend direction was from decreasing to decreasing, and the percentage of overlap was $100 \%$, indicating that the effect of play therapy was maintained in the follow-up phase. Figure 3 shows the trend and level for the $T$ scores of the Oppositional subscale for Participant B's different phases. 


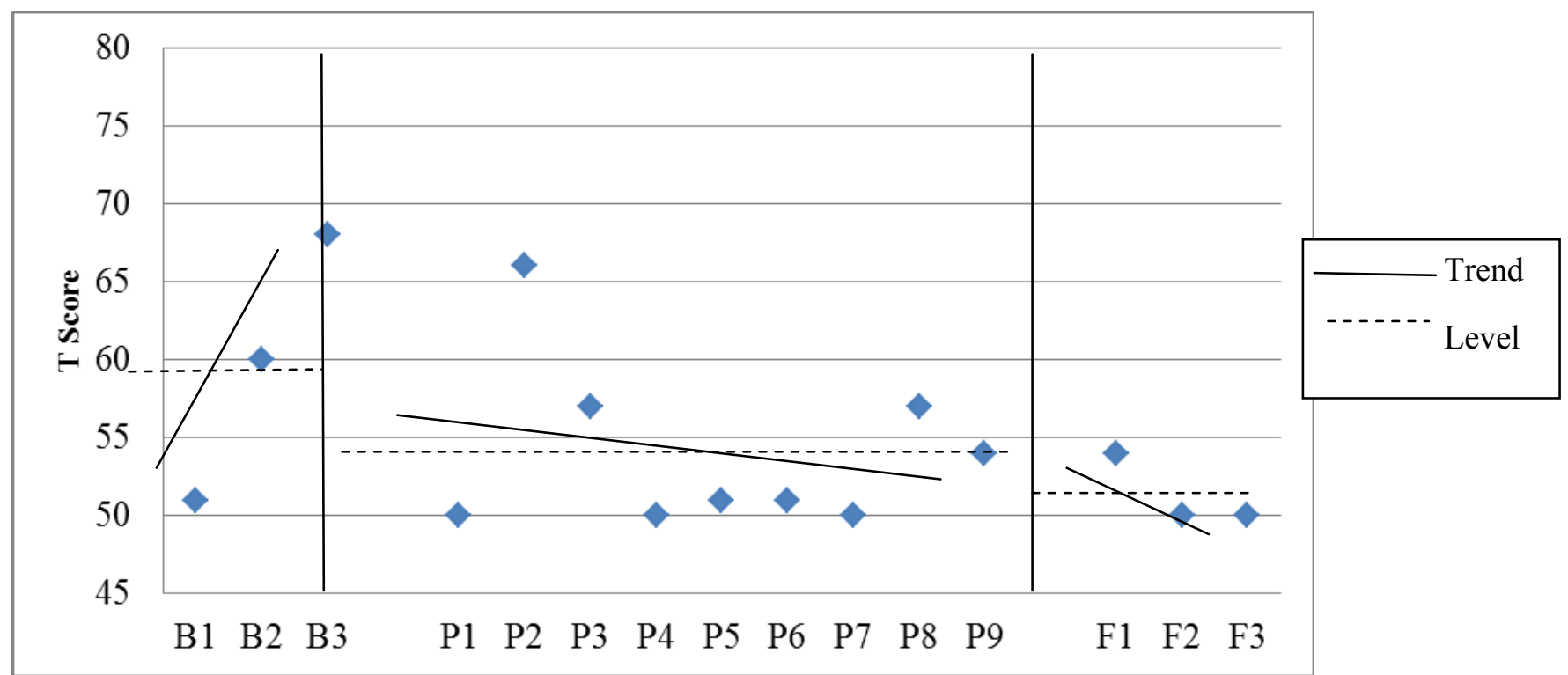

(Baseline Phase)

(Play Therapy Phase)

(Follow-up Phase)

Figure 3. The trend and level of T scores on Oppositional subscale in different phases for Participant B.

In-session progress. Participant B's scores on play characteristics from each play session note are presented in Table 2. According to the treatment notes, the equations and R-squared values of the play behavior trend lines were: Self-Directed Play $\left(\mathrm{y}=0.4667 \mathrm{x}+5.3333 ; \mathrm{R}^{2}=0.8167\right)$, Energy $\left(\mathrm{y}=0.4 \mathrm{x}+5.1111 ; \mathrm{R}^{2}=0.3323\right)$, Sustained Play Behaviors $\left(y=0.5167 x+5.1944 ; R^{2}=0.743\right)$, Destructive $\left(y=7.4444 ; R^{2}=0\right)$, Messy $(y=$ $\left.0.2667 x+6.4444 ; R^{2}=0.1444\right)$, Play Involvement of Play Therapist $\left(y=0.1667 x+2.7222 ; R^{2}=0.1172\right)$, Affect $\left(\mathrm{y}=0.8667 \mathrm{x}+1.2222 ; \mathrm{R}^{2}=0.7017\right)$, Positive Affect $\left(\mathrm{y}=0.3333 \mathrm{x}+4.5556 ; \mathrm{R}^{2}=0.2256\right)$, Age-Appropriate Play $\left(\mathrm{y}=-0.0167 \mathrm{x}+7.5278 ; \mathrm{R}^{2}=0.0016\right)$, and Frustration Tolerance $\left(\mathrm{y}=0.35 \mathrm{x}+5.6944 ; \mathrm{R}^{2}\right.$ $=0.8939$ ), respectively.

Table 2. Participant B's Characteristic Scores of Play Behavior on In-Session Play Therapy Form

\begin{tabular}{|c|c|c|c|c|c|c|c|c|c|}
\hline \multirow[b]{2}{*}{ Characteristic } & \multicolumn{9}{|c|}{ Number of Play Therapy Session } \\
\hline & 1 & 2 & 3 & 4 & 5 & 6 & 7 & 8 & 9 \\
\hline Self-Directed Play & 5 & 7 & 7 & 7 & 7 & 9 & 9 & 9 & 9 \\
\hline Energy & 7 & 5 & 6 & 8 & 4 & 7 & 9 & 10 & 8 \\
\hline Sustained Play Behaviors & 5 & 6 & 8 & 7 & 7 & 9 & 10 & 9 & 9 \\
\hline Destructive & 6 & 7 & 9 & 10 & 6 & 7 & 8 & 6 & 8 \\
\hline Messy & 3 & 8 & 9 & 9 & 9 & 8 & 9 & 7 & 8 \\
\hline Play Involvement of Therapist & 2 & 4 & 4 & 4 & 1 & 5 & 3 & 5 & 4 \\
\hline Affect & 1 & 3 & 5 & 7 & 3 & 6 & 7 & 10 & 8 \\
\hline Positive Affect & 3 & 5 & 7 & 8 & 6 & 7 & 7 & 4 & 9 \\
\hline Age-Appropriate Play & 6 & 8 & 8 & 8 & 8 & 8 & 8 & 5 & 8 \\
\hline Frustration Tolerance & 6 & 6 & 7 & 7 & 8 & 8 & 8 & 8 & 9 \\
\hline
\end{tabular}

The trend directions on all of the above 10 play behaviors were rising, except Destructive which displayed a horizontal line and Age-Appropriate Play which was slightly decreasing. Figure 4 presents the illustration of Participant B's trends on Affect and Frustration Tolerance during play sessions. Based on the results, Participant B's play behaviors demonstrated improvement after obtaining CCPT. 


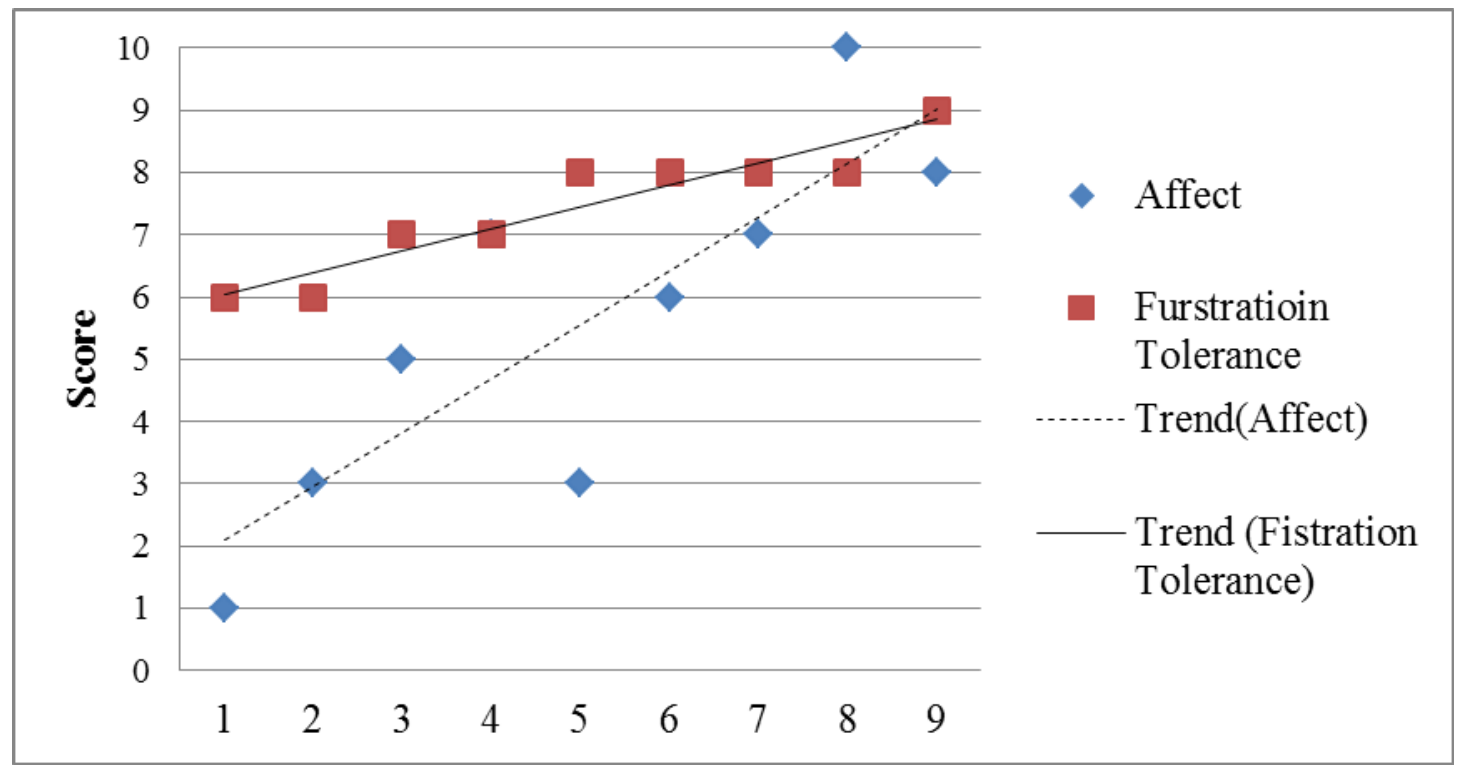

\section{Weeks}

Figure 4. The trends of Energy and Sustained Play Behaviors through play therapy sessions for Participant B.

Intervention effect. For Participant B, the T scores of Externalizing Problems subscale were 67 and 64 on the pre- and post- CBCL, and 73 and 67 on the pre- and post-TRF. Although Participant B's externalizing problems remained in the Clinical range, results showed a decreasing score relative to externalizing behavior problems on both $\mathrm{CBCL}$ and TRF after receiving CCPT intervention.

\section{Discussion}

\subsection{How CCPT Play Therapy Works for Children Exhibiting Internalizing and Externalizing Behavior Problems}

Jacobson and Truax (1991) referred to "clinical significance of the treatment" as "its ability to meet standards of efficacy set by consumers, clinicians, and researchers" (p. 12). Kazdin (1999) defined "clinical significance" as referring to the following:

The practical or applied value or importance of the effect of the intervention-that is, whether the intervention makes a real (e.g., genuine, palpable, practical, and noticeable) difference in everyday life to the clients or to others with whom the client interacts. (p. 332)

Primary indexes of clinical significance are whether participants return to normative levels after receiving interventions. This type of evaluation is particularly helpful when conducting a study without a control or comparison group.

Results of the present study indicated an improvement in Participant A's internalizing behavioral problems after participating in a CCPT intervention as measured by the Internalizing Problem subscale on the CBCL and TRF. The results were consistent with other findings in child psychotherapy (Baggerly \& Jenkins, 2009; Cheng \& Tsai, 2014; Jones \& Carnes-Holt, 2010; Stulmaker \& Ray, 2015).

Similarly, a decreased score was shown on Participant B's externalizing behavior problems. When a child is provided opportunity to express anger and hostile during play sessions, the child's negative feelings are being accepted and understood enabling the child to learn self-control (Moustakas, 1955). With limit setting, a child presenting externalizing behavioral concerns experiences different approaches to expressing feelings and behaviors that result in decreases in the child's oppositional behaviors (Trice-Black et al., 2013). The effectiveness of CCPT with externalizing behaviors has also been reported by previous researchers (Bratton et al., 2013; Cochran et al., 2011; Cochran, Cochran, Fuss, \& Nordling, 2010; Ray et al., 2009; Schumann, 2010).

\subsection{Applied Single-Case Design Methodology to Increase Evidence-Based Practice in Taiwan}

Despite the potential benefit of play therapy, Taiwanese researchers have performed little EPB research. According to Tsai's (2013) systematic review, participants totaled five people or fewer in $80 \%$ of the play therapy studies conducted in Taiwan. Due to the small sample sizes of most studies, promoting increases in EBP research becomes crucial to delivering mental health services to Taiwan's children. 
The use of single-case designs is a way to establish scientific credibility and EBP in the fields of education and psychology (Gallo et al., 2013; Horner et al., 2005; Kratochwill \& Levin, 2010). Additionally, the instruments of choice need to be suitable for several applications and sensitive to slight changes when conducting a single-case design study (Purswell \& Ray, 2014; Ray et al., 2010). To examine children's behavior changes, the present methods involved relying on DOF visual analysis, a known part of the Achenbach System of Empirically Based Assessment (ASEBA), and in-session play therapy notes. Due to ASEBA's demonstrated reliability and validity and to its Chinese version, available since 2009, ASEBA can be used to provide child researchers with empirical data on which to base interventions. To strength EBP research with Asian children, additional single-case design studies may likely enhance the body of research addressing school-based interventions for serving children with psychological difficulties.

\subsection{Issues in Conducting Single-Case Design in School Settings}

APA (2008) indicated that graduate and post-graduate training and consultation programs need to be established to reduce the challenges of implementing and disseminating EBP. Moreover, researchers and practitioners require training to use visual analysis and in-session progress notes (Horner, Swaminathan, Sugai, \& Smolkowski, 2012; Ray, 2011). In Taiwan, most graduate counselling education programs provide introduction to play therapy and research methodology courses. Since play therapy in Taiwan is at an early developmental stage in child psychotherapy research, child professionals-in-training need a graduate course specific to researching play therapy in the future. Child professionals-in-training could gain increased awareness of EBP and single-case design studies through this graduate course.

Additionally, one child research challenge involves the time-consuming demands of teamwork when using standardized observation forms and progress investigation during a single-case design study. The support and collaboration of school districts is essential for balancing the demands of time with the management of unknowns in the research process (Hooper \& Brandt Britnell, 2012). By recognizing the needs of the school and focusing on the advantages of delivering counselling services to children, researchers and practitioners are more likely to gain openness and support from school administrators (Walsh, Barret, \& DePaul, 2007). If this recommendation is applied, the opportunities of conducting EBP research in school settings may increase significantly in the future.

\section{Limitations and Implications}

This study explored the single-case design's applications in school settings in Taiwan. However, several limitations were noted for the sample and data. First, in order to align with the academic calendar of the elementary school, an 18-week intervention was the maximum within a semester. Due to time conflicts, the present study was conducted during a period of 15 weeks. Play therapy intervention was followed by a 3-week observation. To gain a stable trend in a child's typical functioning, future researchers are encouraged to use at least three to five observations (Kazdin, 2011). If the baseline is not stable, the internal validity of the design will be reduced (Purswell \& Ray, 2014).

In this study, the play therapy intervention was shortened from 12-weeks to 9-weeks because of midterm exams and field trips. Hence, future investigations could involve the application of a longitudinal design or more intensive play therapy. Increasing the number of observations at baseline and follow-up phases as well as the number of play therapy sessions could result in greater internal and external validities. In addition, longitudinal studies could provide more information on how play intervention affects children's behavior characteristics.

Because this study is exploratory, only two second-grade male students and not using a comparison group are limitations. Thus, replication studies with a larger sample sizes that include both genders and different age groups as well as studies using a comparison-group design could yield enhanced generalizability. Results thus obtained could enhance CCPT play therapists' and school counselors' knowledge and understanding of children's internalizing and externalizing behavior changes.

Next, obtaining adequate background information and qualitative data are important to interpreting single-case design results (Ray et al., 2010). Although individual feedback was provided to the children's teachers and parents after play therapy was completed, qualitative data (e.g., interviews) was not collected from teachers and parents, due to the nature of the study. Thus, the qualitative perspectives of the children's parents, teachers, or play therapists could guide EBP and enhance future research.

Another limitation might have been due to classroom observer's ratings on the DOF emanating from assumptions about the research participants. To reduce observation bias, observers may need to be kept unaware of participants' background information so that all observations are blind (McConaughy, Ivanova, Antshel, 
Eiraldi, \& Dumenci, 2009). The efficacy of observation might have been affected by the observer's location in the classroom. In this study, the observer was guided by teachers to sit in the back of the classroom. The observer might not have seen some of the participants' non-verbal cues due to the position limitation. Furthermore, Ray's (2011) list of dichotomous characteristics with a continuum measurement of child play behaviors is not a standardized instrument. Ray's measurement tool offers a useful method for gaining systematic perspectives on a child's play change and practicing observation research. However, supervision and continuing education is crucial for play therapists seeking to increase reliability in evaluating a child's emotions and behavior during play sessions. Child-related education courses in graduate-level programs are suggested in order to strengthen the practical and research competence of child mental health professionals. Additionally, a study utilizing Ray's play behavior measurement with children presenting specific psychological concerns is recommended to further explore its application in child research.

\section{Conclusion}

This theory-based study of CCPT as a school counselling intervention involved the use of standardized observation forms along with the CBCL, TRF, and in-session play behavior progress notes. The uniqueness of this study lay in the multiple perspectives drawn from children's parents, teachers, observers, and the play therapist. The study attained the goal of demonstrating the utility of play therapy and single-case assessment designs in Taiwan, where increased emphasis on addressing children's psychological needs has become a priority in school settings.

\section{Acknowledgements}

This work was supported by the National Science Council of Taiwan under Grant NSC 101-2410-H-034-018.

\section{References}

Achenbach, T. M. (1966). The classification of children's psychiatric symptoms: A factor-analytic study. Psychological Monographs: General and Applies, 80, 37.

Achenbach, T. M., \& Rescorla, L. (2001). Manual for the ASEBA School-Age Forms and Profiles. Burlington: University of Vermont, Research Center for Children, Youth, \& Families.

American Psychological Association Task Force on Evidence-Based Practice for Children and Adolescents (APA). (2008). Disseminating evidence-based practice for children and adolescents: A systems approach to enhancing care. Washington, DC: American Psychological Association. Retrieved from http://www.apa.org/practice/resources/evidence/children-report.pdf.

Association for Childhood Education International (ACEI). (2015). The critical place of play in education. Retrieved from http://www.hehd.clemson.edu/downloads/PRTM-Play-Coalition-White-Paper.pdf

Axline, V. (1947). Play therapy: The inner dynamics of childhood. Cambridge, MA: Houghton Mifflin.

Axline, V. (1969). Play therapy (Rev. ed.). New York: Ballantine Books.

Baggerly, J., \& Jenkins,W.W. (2009). The effectiveness of child-centered play therapy on developmental and diagnostic factors in children who are homeless. International Journal of Play Therapy, 18(1), 45-55. https://dx.doi.org/10.1037/a0013878

Blanco, P., Ray, D. C., \& Holliman, R. (2012). Long-term child centered play therapy and academic achievement of children: A follow-up study. International Journal of Play Therapy, 21(1), 1-13. https://dx.doi.org/10.1037/a0026932

Bratton, S. C., Ceballos, P. L., Sheely-Moore, A. I., Meany-Walen, K., Pronchenko, Y., \& Jones, L. D. (2013). Head start early mental health intervention: Effects of child-centered play therapy on disruptive behaviors. International Journal of Play Therapy, 22(1), 28-42. https://dx.doi.org/10.1037/a0030318

Bratton, S. C., Ray, D. C., Rhine, T., \& Jones, L. (2005). The efficacy of play therapy with children: A meta-analytic review of treatment outcomes. Professional Psychology: Research and Practice, 36(4), 376-390. https://dx.doi.org/10.1037/0735-7028.36.4.376

Carmichael, K. D. (2006). Play therapy: An introduction. NJ: Pearson Education.

Centers for Disease Control and Prevention (CDC) (2013). Mental health surveillance among children-United States, 2005-2011. Retrieved from http://www.cdc.gov/mmwr/preview $/ \mathrm{mmwrhtml} / \mathrm{su} 6202 \mathrm{a} 1 . \mathrm{htm}$

Chen, Y, C., Huang, H. L., \& Jao, J. C. (2009). Achenbach system of empirically based assessment (Chinese version). Taipei: Psychological Publishing. 
Cheng, W. Y. \& Tsai, M. H. (2014). The effect of play therapy on socially withdrawn children's behaviors and $\begin{array}{lllll}\text { self-concept. Bulletin of } & \text { Educational }\end{array}$ https://dx.doi.org/10.6251/BEP.20140306

Chengappa, K., Stokes, J. O., Costello, A. H., Norman, M. A., Travers, R. M., \& McNeil, C. B. (2013). Parent-child interaction therapy for severe sibling conflict in young children. Journal of Communications Research, 5(1), 31-47.

Cochran, J. L., Cochran, N. H., Cholette, A., \& Nordling, W. J. (2011). Limits and relationship in child-centered play therapy: Two case studies. International Journal of Play Therapy, 20(4), 236-251. https://dx.doi.org $/ 10.1037 / \mathrm{a} 0025425$

Cochran, J. L., Cochran, N. H., Fuss, A., \& Nordling, W. J. (2010). Outcomes and stages of child-centered play therapy for a child with highly disruptive behavior driven by self-concept issues. Journal of Humanistic Counseling, Education and Development, 49(2), 231-246. https://dx.doi.org /10.1002/j.2161-1939.2010.tb00100.x

Cohen, J. (1988). Statistical power analysis for the behavioral sciences $\left(2^{\text {nd }}\right.$ ed.). Hillsdale, NJ: Erlbaum.

Copeland, W. E., Shanahan, L., Costello, E. J., \& Angold, A. (2009). Childhood and adolescent psychiatric disorders as predictors of young adult disorders. Archives of General Psychiatry, 66(7), 764-772. https://dx.doi.org /10.1001/archgenpsychiatry.2009.85

Dishion, T. J., \& Patterson, G. R. (2006). The development and ecology of antisocial behavior in children and adolescents. In D. Cicchetti \& D. J. Cohen (Eds.), Developmental psychopathology $\left(2^{\text {nd }}\right.$ ed., Vol. 3, pp. 503-541). New York: Wiley.

Erikson, E. (1977). Toys and reasons: Stages in the ritualization of experiences. New York: Norton.

Gast, D. L. (2010). Single subject research methodology in behavioral sciences. New York, NY: Routledge.

Gallo, K. P., Comer, J. S., \& Barlow, D. H. (2013). Single-case experimental designs and small pilot trial designs. In J. S. Comer \& P. C. Kendall (Eds.), The Oxford handbook of research strategies for clinical psychology (pp. 24-39). New York, NY: Oxford University Press. https://doi.org/10.1093/oxfordhb/9780199793549.013.0003

Ginsburg, K. R. (2007). The importance of play in promoting healthy child development and maintaining strong parent-child bonds. Pediatrics, 11, 182-191. https://dx.doi.org /10.1542/peds.2006-2697

Guerney, L. (2001). Child-centered play therapy. International Journal of Play Therapy, 10(2), 13-31. https://dx.doi.org /10.1037/h0089477

Herrman, H., Goldstone, S., \& McGorry, P. (2014). Research and practice in youth mental health: An Australian perspective. Taiwanese Journal of Psychiatry (Taipei), 28(3), 138-147.

Hooper, L. M., \& Brandt Britnell, H. (2012). Mental health research in K-12 schools: Translating a systems approach to university-school partnerships. Journal of Counseling and Development, 90(1), 81-90. https://dx.doi.org /10.1111/j.1556-6676.2012.00011.x

Horner, R. H., Swaminathan, H., Sugai, G., \& Smolkowski, K. (2012). Considerations for the systematic analysis and use of single-case research. Education and Treatment of Children, 35, 269-290. https://dx.doi.org /10.1353/etc.2012.0011

Horner, R. H., Carr, E. G., Halle, J., McGee, G., Odom, S., \& Wolery, M. (2005). The use of single-subject research to identify evidence-based practice in special education. Exceptional Children, 71, 165-179. https://doi.org/10.1177/001440290507100203

Horney, K. (1937). The neurotic personality of our time. New York; Norton.

Hwang, K. K. (2012). Foundations of Chinese psychology: Confucian social relations (Vol. 1). New York: Springer Science \& Business Media. https://doi.org/10.1007/978-1-4614-1439-1

Jacobson, N. S., \& Truax, P. (1991). Clinical significance: A statistical approach to defining meaningful change in psychotherapy research. Journal of Consulting and Clinical Psychology, 59, 12-19. https://doi.org/10.1037/0022-006X.59.1.12

Jones, E. M., \& Carnes-Holt, K. (2010). The efficacy of intensive individual child-centered play therapy for chronically ill children. In J. Baggerly, D. Ray, \& S. Bratton's (Eds.), Child-centered play therapy research: 
The evidence base for effective practice (pp. 51-67). Hoboken, NJ: Wiley. https://doi.org/10.1002/9781118269626.ch3

Kazdin, A. E. (1999). The meanings and measurement of clinical significance. Journal of Consulting and Clinical Psychology, 67, 300-307. https://doi.org/10.1037/0022-006X.67.3.332

Kazdin, A. E. (2011). Single-case research designs: Methods for clinical and applied settings (2 ${ }^{\text {nd }}$ ed.). New York, NY: Oxford University Press.

Korner, A. F. (1949). Some aspects of hostility in young children. New York: Grune \& Stratton. https://doi.org/10.1037/14542-000

Kratochwill, T. R. \& Levin, J. R. (2010). Enhancing the scientific credibility of single-case intervention research: Randomization to the rescue. Psychological Methods, 15(2), 124-144. https://doi.org/10.1037/a0017736

Landis, J. R., \& Koch, G. G. (1977). The measurement of observer agreement for categorical data. Biometrics, 33(1), 159-174. https://doi.org/10.2307/2529310

Landreth, G. L. (2012). Play therapy: The art of the relationship ( ${ }^{\text {rd }}$ ed.). New York: Routledge.

Landreth, G. L., Ray, D. C., \& Bratton, S. C., (2009). Play therapy in elementary schools. Psychology in the Schools, 46(3), 281-289. https://doi.org/10.1002/pits.20374

Lin, Y., \& Bratton, S. C. (2015). A meta-analytic review of child-centered play therapy approaches. Journal of Counseling and Development, 93(1), 45-58. https://doi.org/10.1002/j.1556-6676.2015.00180.x

Marchand-Reilly, J. F. (2012). The role of fathers' depressive symptoms and lax and over-reactive discipline in children's externalizing and internalizing behaviors. Journal of Adult Development, 19(4), 181-189. https://doi.org/10.1007/s10804-012-9145-3

Masten, A. S., Roisman, G. I., Long, J. D., Burt, K. B., Obradovic, J., Riley, J. R., ...Tellegen, A. (2005). Developmental cascades: Linking academic achievement and externalizing and internalizing symptoms over 20 years. Developmental Psychology, 41(5), 733-746. https://doi.org/10.1037/0012-1649.41.5.733

McConaughy, S. H., \& Achenbach, T. M. (2009). Manual for the ASEBA Direct Observation Form. Burlington, VT: University of Vermont, Research Center for Children, Youth, \& Families.

McDougall, D., \& Smith, D. (2006). Recent innovations in small-N designs for research and practice in professional school counseling. Professional School Counseling, 9(5), 392-400. https://doi.org/10.5330/prsc.9.4.h2r747nq1r837405

Mental Health America. (2009). Factsheet: Recognizing mental health problems in children. Retrieved from http://www.mhajax.org/images/recognize_mh_children.pdf

Mills, B., \& Allan, J. (1992). Play therapy with the maltreated child: Impact upon aggressive and withdrawn patterns of interaction. International Journal of Play Therapy, 1, 1-20. https://doi.org/10.1037/h0090231

Ministry of Education in Taiwan. (2011). Primary and Junior High School Act. Retrieved from http://edu.law.moe.gov.tw/EngLawContent.aspx?Type=E\&id=142\&KeyWord=0e5\%9c\%8b\%e6\%b0\%91 $\%$ e6\%95\%99\%e8\%82\%b2\%e6\%b3\%95

Ministry of Education in Taiwan. (2014). Student Guidance Act. Retrieved from $\mathrm{http} / /$ www.edu.tw/e_board/detail.aspx?Node=1075\&Page=23735\&Index=4\&WID=65cdb365-af62-48cc-9 9d9-f9e2646b5b70

Morgan, D. L., \& Morgan, R. K. (2009). Single-case research methods for behavioral and health sciences. Los Angeles: Sage. https://doi.org/10.4135/9781483329697

Moustakas, C. E. (1955). Emotional adjustment and the process of play therapy. Journal of Genetic Psychology, 86, 79-99. https://doi.org/10.1080/00221325.1955.10532898

Nordling, W., \& Guerney, L. (1999). Typical stages in the child-centered play therapy process. The Journal for the Professional Counselor, 14(1), 17-23.

O’Connor, K. J., Schaefer, C. E., \& Braverman, L. D. (2016). Handbook of play therapy (2 ${ }^{\text {nd }}$ ed.). Somerset, NJ: John Wiley \& Sons, Inc.

Okpych, N. J. \& Yu, J. L. (2014). A historical analysis of evidence-based practice in social work: The unfinished journey toward an empirically grounded profession. Social Service Review, 88(1), 3-58. https://doi.org/10.1086/674969 
Paynter, R. (2009). Evidence-based research in the applied social sciences. Reference Services Review, 37(4), 435-450. https://doi.org/10.1108/00907320911007038

Piaget, J. (1962). Play, dreams, and imitation in childhood. New York: Norton.

Purswell, K. E. \& Ray, D. C. (2014). Research with small samples: Considerations for single case and randomized small group experimental designs. Counseling Outcome Research and Evaluation, 5(2), 116-126. https://doi.org/10.1177/2150137814552474

Ray, D. C. (2011). Advanced play therapy: Essential conditions, knowledge, and skills for child practice. New York: Routledge.

Ray, D. C., Armstrong, S., Balkin, R., \& Jayne, K. (2015). Child centered play therapy in the schools: Review and meta-analysis. Psychology in the Schools, 52(2), 107-123. https://doi.org/10.1002/pits.21798

Ray, D. C., Blanco, P., Sullivan, J., \& Holliman, R. (2009). An exploratory study of child-centered play therapy with aggressive children. International Journal of Play Therapy, 18, 162-175. https://doi.org/10.1037/a0014742

Ray, D. C., \& McCullough, R. (2015). Evidence-based practice statement: Play therapy. Retrieved from http://www.a4pt.org/?page=EvidenceBased

Ray, D. C., Minton, C. A., Schottelkorb, A. A., Brown, A. G. (2010). Single-case design in child counseling research: Implications for counselor education. Counselor Education and Supervision, 49, 193-208. https://doi.org/10.1002/j.1556-6978.2010.tb00098.x

Ray, D. C., Schottelkorb, A., \& Tsai, M. H. (2007). Play therapy with children exhibiting symptoms of attention deficit hyperactivity disorder. International Journal of Play Therapy, 16 (2), 95-111. https://dx.doi.org/10.1037/1555-6824.16.2.95

Rubin, A. (2012). Statistics for evidence-based practice and evaluation ( $3^{\text {rd }}$ ed.). Belmont, CA: Brooks/Cole, Cengage Learning.

Rubin, A., \& Parrish, D. E. (2012). Improving the scientific base of social work practice. In C. N. Dulmus, \& K. M. Sowers's (Eds.), The profession of social work: Guided by history, led by evidence (pp. 203-223). Hoboken, NJ: John Wiley \& Sons, Inc.

Rubin, K. H., Coplan, R. J., \& Bowker, F. C. (2009). Social withdrawal in childhood. Annual Review of Psychology, 61, 141-171. https://doi.org/10.1146/annurev.psych.60.110707.163642

Russ, S. W. (2004). Play in child development and psychotherapy: Toward empirically supported practice. Mahwah, NJ: Erlbaum.

Schoemaker, K., Mulder, H., Dekovic, M., \& Matthys, W. (2013). Executive functions in preschool children with externalizing behavior problems: A meta-analysis. Journal of Abnormal Child Psychology, 41(3), 457-471. https://dx.doi.org /10.1007/s10802-012-9684-x

Schumann, B. (2010). Effectiveness of child centered play therapy for children referred for aggression in elementary school. In J. Baggerly, D. Ray, \& S. Bratton's (Eds.), Child-centered play therapy research: The evidence base for effective practice (pp. 193-208). Hoboken, NJ: Wiley.

Soni, A. (2014). The five most costly children's conditions, 2011: Estimates for U.S. civilian noninstitutionalized children, ages 0-17. Statistical Brief No.434. Rockville, MD: Agency for Healthcare Research and Quality. Retrieved from http://www.meps.ahrq.gov/mepsweb/data_files/publications/st434/stat434.shtml

Stulmaker, H., \& Ray, D. (2015). Child-centered play therapy with young children who are anxious: A controlled trial. Children and Youth Services Review, 57, 127-133. https://doi.org/10.1016/j.childyouth.2015.08.005

Sturaro, C., Van Lier, P. A., Cuijpers, P., \& Koot, H. M. (2011). The role of peer relationships in the development of early school-age externalizing problems. Child Development, 82(3), 758-765. https://doi.org/10.1111/j.1467-8624.2010.01532.x

Tawney, J. W., \& Gast, D. L. (1984). Single subject research in special education. Columbus, OH: Charles, E. Merrill.

Tsai, M. H. (2013). Research in play therapy: A 10-year review in Taiwan. Children and Youth Services Review, 35(1), 25-32. https://doi.org/10.1016/j.childyouth.2012.10.016 
Tsai, M. H., \& Ray, D. C. (2011). Children in therapy: Learning from evaluation of university-based community counseling clinical services. Children and Youth Services Review, 33(6), 901-909. https://doi.org/10.1016/j.childyouth.2010.12.011

Trice-Black, S., Bailey, C., \& Riechel, M. (2013). Play therapy in school counseling. Professional School Counseling, 16(5), 303-312. https://doi.org/10.5330/PSC.n.2013-16.303

VanFleet, R., Sywulak, A. E., \& Sniscak, C. C. (2010). Child-centered play therapy. New York: The Guilford Press.

Vygotsky, L. S. (1967). Play and its role in the mental development of the child. Soviet Psychology, 5(3), 6-18. https://doi.org/10.2753/RPO1061-040505036

Walsh, M. E., Barrett, J. G., \& DePaul, J. (2007). Day-to-day activities of school counselor: Alignment with new directions in the field and the ASCA national model. Professional School Counseling, 10(4), 370-378. https://doi.org/10.5330/prsc.10.4.47p342040286mw72

Wang, C. C., Jang, G. B., Lian, T. J., \& Wang, W. S. (2006). The meta-analysis of play therapy effects in Taiwan. Paper presented at 2006 Annual Association for Taiwan Play Therapy Conference, Hsinshu, Taiwan.

West, J. (1996). Client-centered play therapy ( $2^{\text {nd }}$ ed.). London: Hodder Arnold.

Wettig, H. H. G., Coleman, A. R., \& Geider, F. J. (2011). Evaluating the effectiveness of theraplay in treating shy, socially withdrawn children. International Journal of Play Therapy, 20(1), 26-37. https://doi.org/10.1037/a0022666

White, B., Jarrett, M., \& Ollendick, T. (2013). Self-regulation deficits explain the link between reactive aggression and internalizing and externalizing behavior problems in children. Journal of Psychopathology \& Behavioral Assessment, 35(1), 1-9. https://doi.org/10.1007/s10862-012-9310-9

World Health Organization. (2015). Child and adolescent mental health. Retrieved from http://www.who.int/mental_health/maternal-child/child_adolescent/en/

O'Connor, K. J., Schaefer, C. E., \& Braverman, L. D. (2016). Handbook of play therapy (2 ${ }^{\text {nd }}$ ed.). Somerset, NJ: John Wiley \& Sons, Inc.

\section{Copyrights}

Copyright for this article is retained by the author(s), with first publication rights granted to the journal.

This is an open-access article distributed under the terms and conditions of the Creative Commons Attribution license (http://creativecommons.org/licenses/by/4.0/). 